\title{
Synthesis and Characterization of Kalata B2 Cyclotide (GLPVCGETCFGGTCNTPGCSCTWPICTRD) on Wang Resin, as Solid Support
}

\author{
Verma Deepshikha*, Pillai V. N. Rajasekharan \\ Department of Chemistry, Mewar University, Gangrar, Chittorgarh, Rajasthan, India \\ Email: *deepshikhaverma0341@gmail.com
}

How to cite this paper: Deepshikha, V. and Rajasekharan, P.V.N. (2020) Synthesis and Characterization of Kalata B2 Cyclotide (GLPVCGETCFGGTCNTPGCSCTWPICTR D) on Wang Resin, as Solid Support. Open Journal of Medicinal Chemistry, 10, 46-55. https://doi.org/10.4236/ojmc.2020.102004

Received: April 22, 2020

Accepted: May 29, 2020

Published: June 2, 2020

Copyright ( 2020 by author(s) and Scientific Research Publishing Inc. This work is licensed under the Creative Commons Attribution International License (CC BY 4.0).

http://creativecommons.org/licenses/by/4.0/

\begin{abstract}
With the help of the solid phase peptide synthesizing method, we synthesized Kalata B2 cyclotide and the final product was purified by preparative HPLC. The sequence of Kalata B2 is GLPVCGETCFGGTCNTPGCSCTWPICTRD and its $\mathrm{m} / \mathrm{z} \mathrm{M}+\mathrm{H}$ mass is 2955.53. It had been first isolated from Oldenlandia affinis plant leaves extract which belongs to Rubiaceae family. The synthesis of Kalata B2 has been characterized through UPLC/MS, LC/MS, CD, $1 \mathrm{HNMR}$, and IR.
\end{abstract}

\section{Keywords \\ UPLC, LC/MS, 1HNMR, IR}

\section{Introduction}

Cyclotides are a unique and growing family of head-to-tail cyclized peptides that also contain six cysteine residues oxidized into three disulfide bonds built a cystine knot motif (CCK) [1]. The so-called cyclic cystine knot (CCK) renders the cyclotides exceptionally rigidity, resistance to thermal and chemical denaturation, and enzymatic stability against degradation [2]. Kalata B2 is a cyclotide and cyclotide is one of the types of cyclopeptides in which two main forms of cyclic bonds are present. These two main forms of peptide cyclization are: 1) Cyclization by the formation of the amide bond between the $\mathrm{N}$-terminal and the C-terminal amino acid residues (head-to-tail cyclization) [3] and 2) cyclization involving the side chains (S-S bond) of individual amino acids (backbone to backbone cyclization) [4]. Among the various molecules that plants produce for 
defense against pests and pathogens, cyclotides act as exceptionally stable with unique structurally. They occur in several species of plant families such as $\mathrm{Ru}$ biaceae, Violaceae, Cucurbitaceae, Fabaceae, and Solanaceae with an individual plant producing up to hundreds of different cyclotides [5]. Kalata B2 occurs naturally in tropical plants from the Rubiaceae or Violaceae families and is classified as a member of the Möbius cyclotide family [6]. Structure of Kalata B2 is shown in Figure 1.

Cyclotides are divided into two main subfamilies-Möbius and bracelet. If a conceptual twist in the cyclic backbone formed by the cis X-Proline peptide bond is present in loop 5 as shown in Figure 2 is called Mobius Cyclotide and if the conceptual twist in a loop is absent, called Bracelet cyclotide. Approximately two-thirds of cyclotides are in the bracelet subfamily and one-third belongs to the Möbius subfamily. There is one more third subfamily of cyclotides, which is trypsin inhibitor subfamily, also known as the cyclic knottins. Although cyclotides from the trypsin inhibitor subfamily have sequences which are quite different from the other two subfamilies but their structures are highly similar [7].

Cyclotides are widely used in many areas like cyclotides as probes of membrane binding, cyclotides as probes of biosynthetic pathways for peptide cyclization, cyclotides as probes of protease specificity and function, and cyclotides as probes of receptor binding and specificity, with the potential for them to be developed as drug leads [7]. Kalata B2 is biological active molecule and has many medicinal uses and earlier reported to have insecticidal activity against $H$. armigera larvae [8]. In this paper, we report the synthesis of Kalata B2 by using chemical synthesizing method and it is solid phase peptide synthesis (SPPS). The synthesized Kalata B2 has been characterized by UP-LC, LC-MS, 1HNMR, FTIR. The objective of the study was to characterize the Kalata B2 obtained by SPPS method in order to validate the usefulness of the cost effective, low laborious and high yield producing method for the synthesis of Kalata B2.

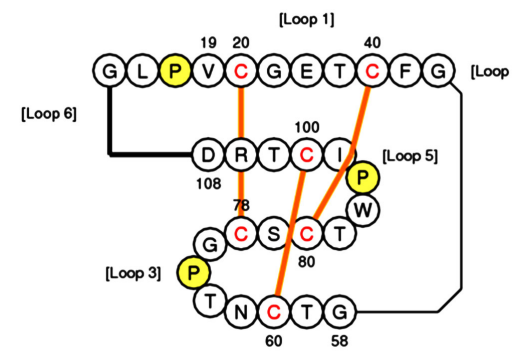

Figure 1. Structure of Kalata B2 cyclotide.

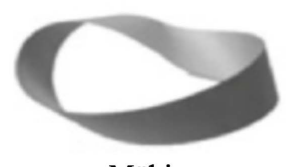

Möbius

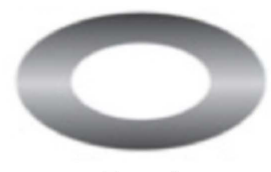

Bracelet

Figure 2. Subfamilies of cyclotide. 


\section{Materials and Method}

\subsection{Instrumental Details}

Column chromatography was performed over microporous resin (Diaion HP-20 sigma aldrich. Co., USA). Thin layer chromatography was performed on silicagel plates (Merck Millipore). The ninhydrin reagent was used for spraying on TLC Plates was sigma aldrich. Co., USA HPLC was carried out on an Agilent 1100 series system with a UV detector at variable wavelengths of 206, 215, 225, 254, and $280 \mathrm{~nm}$. Masses were analyzed on a LCMS-Waters SYNAPT G2 with 2D nano ACQUITY System. The amide N-H stretching band (-NH), the amide I band around $1615 \mathrm{~cm}^{-1}(-\mathrm{C}=\mathrm{O})$, and the amide II band around $1550 \mathrm{~cm}^{-1}(-\mathrm{NH})$ are the characteristic features that usually are examined by FT-IR/Raman Spectrometer with Microscope-Varian 7000 FTIR, Varian FT-Raman and Varian 600 UMA. CD spectroscopy detects the wavelength dependence of this ellipticity, and positive or negative $\mathrm{CD}$ is observed when either the right- or the left-circular polarized component is absorbed more strongly. $\mathrm{CD}$ is a method of choice for the quick determination of peptide secondary structure and we used Circular Dichroism (CD) Spectrometer with Stop Flow-Applied PhotoPhysics Chirascan to take the CD specta. For 1HNMR spectra the Bruker AVIII $500 \mathrm{MHz}$ instrument had been used. All solvents and glassware used for isolation were obtained from sigma Aldrich Company. We utilized all these facilities from AIRF department of Jawahar Lal University, New Delhi.

\subsection{Materials}

In the synthesis of PNC-28 Peptide the reagents used are obtained from Sigma-Aldrich Company and these are Wang Resin, Fmoc protected amino acids (ETFSDLWKLL), additives (HOBT and HBTU, HATU and HOAT), Diisopropylcarbodiimide, DMF, DCM, IPA, IPE, TFA, DI water, KCN, Pyridine, n-Butanol, Ninhydrin, Phenol, trifluoroacetic acid $(82.5 \% \mathrm{v} / \mathrm{v})$, phenol $(5 \% \mathrm{v} / \mathrm{v})$, water $(5 \% \mathrm{v} / \mathrm{v})$, thioanisole $(5 \% \mathrm{v} / \mathrm{v}), 1,2$-ethanedithiol $(2.5 \% \mathrm{v} / \mathrm{v})$, Diethyl ether. The equipment used is also obtained from Sigma-Aldrich Company and they are frit glass vessel, caframo, stopper test-tubes, weighing machine, round bottom flask, desiccator, lyophilizer.

\subsection{Method}

We selected the Wang resin because the C-terminal of our peptide is $\mathrm{COOH}$. Swell the wang resin ( $1 \mathrm{~g}$ in quantity and its loading capacity is $1.5 \mathrm{mmol})$ in DMF for overnight and after swelling remove DMF from the frit vessel. Loading of first aspartic amino acid (D) and this amino acid is orthogonally protected whose alpha C-terminal $\mathrm{COOH}$ is protected with $\mathrm{t}-\mathrm{Bu}$ and side chain carboxyl group is free to get attach or couple with Wang resin. Took $\mathrm{D}=308.62 \mathrm{~g}$, HOBT $=0.101$, DMAP crystal $=$ one pellet. Add DIC $=116.8$ microliters. Mix all the above weighed quantities in $2 \mathrm{ml}$ of $4 \%$ DIPEA. Mixed well over vortex mixer. Added this content to drain bed of swollen WANG resin. Capped the vessel and 
started mixing or coupling on Caframo overnight. Washing the material after overnight. Did Kaiser's Test for coupling: Took 10 - 15 beads of resin in a test tube. Added 2 - 3 drops of Kaiser's solution. Heated the tube at 110 degrees Celsius for five minutes. The result was colorless solution and beads were also colorless which showed the complete coupling. Then did Deprotection of Fmoc group of amino acid with $20 \%$ Piperidine for half-an-hour. Again, washing the material. Did Kaiser's Test for deprotection: Took 10 - 15 beads of resin in a test tube. Added 2 - 3 drops of each reagent A, reagent B, reagent C. Heated the tube at 110 degrees Celsius for five minutes. The result was blue colored solution and dark blue colored beads. It showed the complete deprotection [11] [12]. Repeat these steps (coupling, washing, Kaiser's test, deprotection, washing, Kaiser's test) until the final sequence had been completed.

A) N-to-C or head-to-tail cyclization scheme for Linear sequence of $\mathrm{Ka}$ -

\section{lata B2}

Washed and bring resin in water

- $3 \times \operatorname{DMF}(2 \mathrm{ml}) \times 4 \mathrm{~min}$

- $3 \times \operatorname{DCM}(2 \mathrm{ml}) \times 4 \mathrm{~min}$

- $2 \times \operatorname{IPA}(2 \mathrm{ml}) \times 4 \mathrm{~min}$

- $5 \times$ water $(3 \mathrm{ml}) \times 4 \mathrm{~min}$

Added 2 - $3 \mathrm{ml}$ of 25\% TFA. Incubated the washed material at room temperature for two hours. Washed again. Remove Fmoc from first N-terminal of first amino acid Gylcine. Did testing for deprotection after washing. Then added HOAT and HATU in $3 \mathrm{ml}$ of $4 \%$ DIPEA in DMF. Incubated it for overnight. Washed routinely $(3 \times \mathrm{DMF}(2 \mathrm{ml}) \times 4 \mathrm{~min}, 3 \times \mathrm{DCM}(2 \mathrm{ml}) \times 4 \mathrm{~min}, 2 \times \mathrm{IPA}$ $(2 \mathrm{ml}) \times 4 \mathrm{~min})$. Washed with plenty of water (5 - 6 times). Left the resin with aerated water. Repeated step-10 three times. Washed again.

- $3 \times$ water $(2 \mathrm{ml}) \times 4 \mathrm{~min}$

- $2 \times \operatorname{IPA}(2 \mathrm{ml}) \times 4 \mathrm{~min}$

- $2 \times \operatorname{DCM}(2 \mathrm{ml}) \times 4 \mathrm{~min}$

- $2 \times \operatorname{DMF}(2 \mathrm{ml}) \times 4 \mathrm{~min}$

- $2 \times \operatorname{DCM}(2 \mathrm{ml}) \times 4 \mathrm{~min}$

- $2 \times \operatorname{IPA}(2 \mathrm{ml}) \times 4 \mathrm{~min}$

- $2 \times \operatorname{IPE}(2 \mathrm{ml}) \times 4 \mathrm{~min}$

The second last step is to dry the material by using vacuum for two hours and the last step is the cleavage and precipitation of Kalata B2 from wang resin with cocktail-K and diethyl-ether. Lyophilize the final material and did LC-MS to check the synthesized Kalata B2.

B) Cys-Cys bond or side chain-to-side chain cyclization Scheme of Linear Kalata B2

Kalata B2 Cyclotide containing three disulfide bonds requires three pairs of cysteine residues that can be independently deprotected. In this case, Fmoc chemistry is preferred over Boc chemistry because there is a greater selection of independently deprotected cysteine derivatives available. The set of orthogonally protected Cysteine (trt), Cysteine (stbu), Cysteine (tbu) are used to form the cys- 
tine-cystine bonds (between the Sulphur atoms of two cysteine molecules and total 3 cystine bonds) for synthesis of Kalata B2 cyclotide. The detailed method of cystine-cystine bond formation has already been given in earlier publication "[9] [10]" which we used in our synthesis. But in our synthesis method, we used different orthogonally protected cysteine amino acids as mentioned above to form the cystine-cystine bond by air oxidation. We also made three cystine-cystine bonds in between the synthesis and at last did the backbone cyclization. Figure 3 presents the scheme for cyclization of solid phase peptide synthesis in general.

\section{Results and Discussion}

Figure 4 represents the UP-LC spectra of crude Kalata B2 cyclotide which we synthesized with solid phase peptide synthesis method. After checking the purity yield, we did finally purification by RP-HPLC. Before purification we got $\approx 90$ $\mathrm{mg}$ yield and after purification we got $\approx 40 \mathrm{mg}$ yield of Kalata $\mathrm{B} 2$ cyclotide.

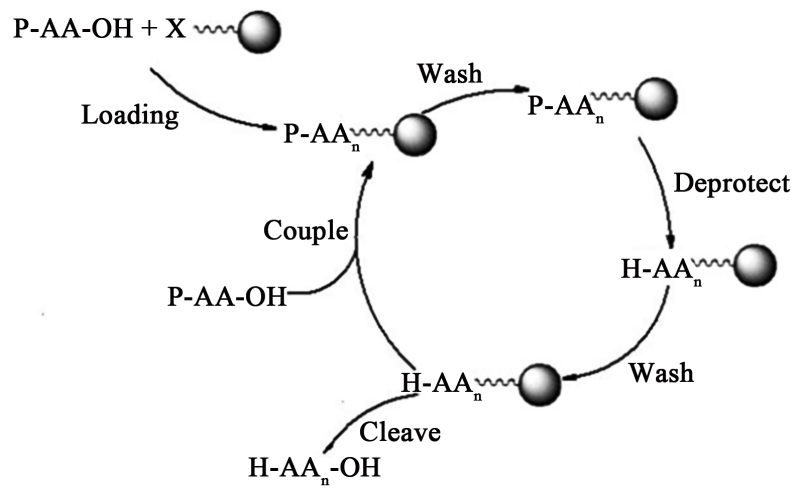

Figure 3. Scheme for cyclization of solid phase peptide synthesis in general.

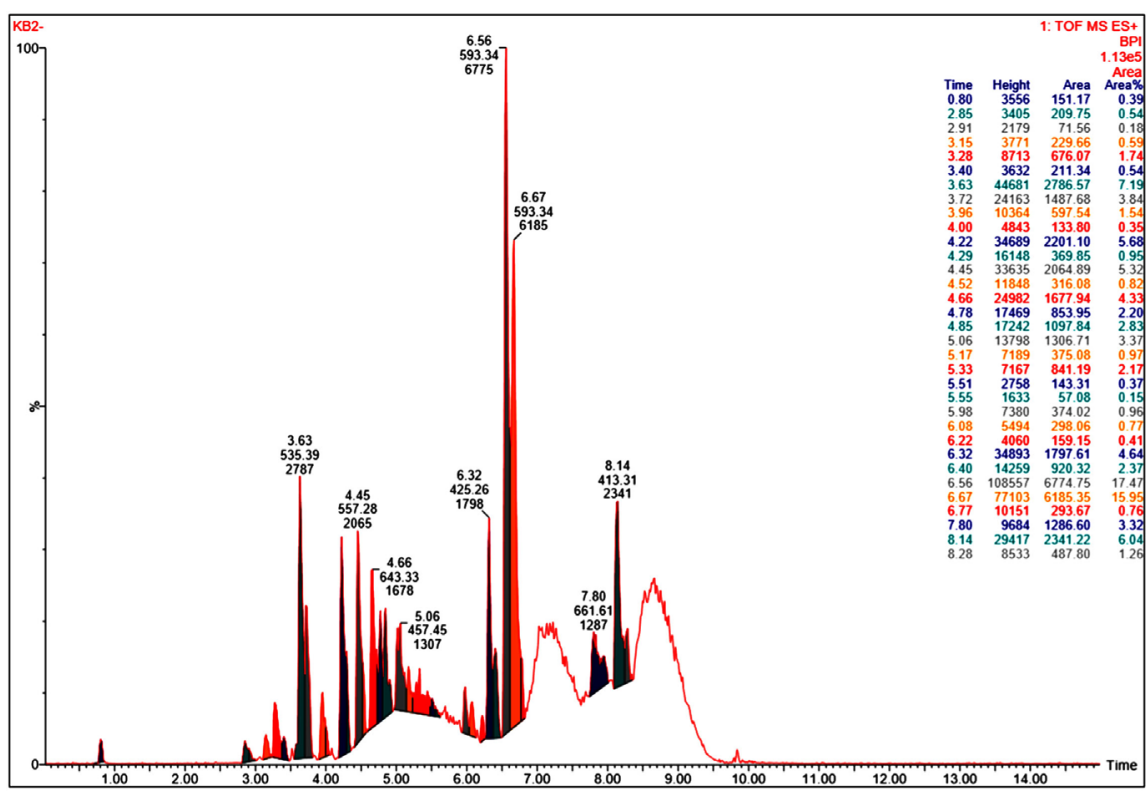

Figure 4. UPLC-MS of crude Kalata B2 cyclotide. 
Figure 5 represents the successful synthesis of Kalata B2 cyclotide and was analysed through liquid chromatography mass spectroscopy (LC-MS) which reveals the presence of Kalata B2 cyclotide with a molecular mass $\approx 2955 \mathrm{~g} / \mathrm{mol}$ or $\mathrm{m} / \mathrm{z} \mathrm{H}+5 \approx 593 \mathrm{~g} / \mathrm{mol}$ or $\mathrm{m} / \mathrm{z} \mathrm{H}+4 \approx 735$.

Figure 6 represent the ${ }^{1} \mathrm{HNMR}$ of Kalata B2 cyclotide. In ${ }^{1} \mathrm{HNMR}$ spectra the observed chemical shift values of Kalata B2 cylotide residues with respect to $\mathrm{HN}$, $\mathrm{HA}, \mathrm{HB}$ and others are: for $\mathrm{D} 29-\mathrm{HN}$ is $9.44, \mathrm{HA}$ is $4.36, \mathrm{HB}$ is $2.81,3.33$; for $\mathrm{R} 28-\mathrm{HN}$ is $8.68, \mathrm{HA}$ is $4.75, \mathrm{HB}$ is 1.71 , others are QG 1.46, QD 3.19, HE 6.98; for $\mathrm{T} 27 \mathrm{HN}$ is $9.88, \mathrm{HA}$ is $5.06, \mathrm{HB}$ is 3.75 , others are QG2 0.9 ; $\mathrm{C} 26-\mathrm{HN}$ is 7.66 , $\mathrm{HA}$ is $5.1, \mathrm{HB}$ is $2.79,3.28$; for $\mathrm{I} 25 \mathrm{HN}$ is $8.35, \mathrm{HA}$ is $4.18, \mathrm{HB}$ is 1.8 , others are QG2 1.11, QG1 1.34, QD1 0.71; for P24-HA is 3.36, HB is $-0.91,0.67$, others are HG2 0.95, HG1 1.16, HD2 3.11, HD1 3.18; for W23-HN is 7.79, HA is 4.04, HB is 4.18, others are HZ3 7.1, HZ2 7.72, HH2 7.35, HE3 7.44, HE1 10.32, HD1 7.36; for T22-HN is 8.73, HA is 4.51, HB is 4.18, others are QG2 1.14; for C21-HN is 8.97, $\mathrm{HA}$ is $4.68, \mathrm{HB}$ is $2.72,3.06$; for $\mathrm{S} 20-\mathrm{HN}$ is $9.53, \mathrm{HA}$ is $9.53, \mathrm{HB}$ is 3.65 , 3.73; for $\mathrm{C} 19-\mathrm{HN}$ is $7.72, \mathrm{HA}$ is $5.3, \mathrm{HB}$ is 5.3 ; for $\mathrm{G} 18-\mathrm{HN}$ is $8.79, \mathrm{HA}$ is 3.74 , 3.74; for P17-HA is 4.31, HB is 2.38, 2.38 and others are HG2 2.07; for T16-HN is $8.65, \mathrm{HA}$ is $4.5, \mathrm{HB}$ is 4.25 , others are QG2 1.38 ; for $\mathrm{N} 15-\mathrm{HN}$ is $8.8, \mathrm{HA}$ is 4.73 , $\mathrm{HB}$ is 4.25 , others are $\mathrm{HD} 226.93$, $\mathrm{HD} 21 \mathrm{7.68}$; for $\mathrm{C} 14-\mathrm{HN}$ is 8.46 , HA is 4.64 , $\mathrm{HB}$ is $2.79,2.99$; for $\mathrm{T} 13-\mathrm{HN}$ is $7.8, \mathrm{HA}$ is $4.76, \mathrm{HB}$ is 4.1 , others are QG2 1.19; for G12-HN is $8.1, \mathrm{HA}$ is $4.13,4.59$; for G11-HN is 8.46 , HA is $3.9,4.45$; for $\mathrm{F} 10-\mathrm{HN}$ is $8.71, \mathrm{HA}$ is $4.15, \mathrm{HB}$ is $3.05,3.36$, others are QE 7.29, QD 7.4; for $\mathrm{C} 9-\mathrm{HN}$ is $8.5, \mathrm{HA}$ is $5.19, \mathrm{HB}$ is $2.65,3.32$; for $\mathrm{T} 8-\mathrm{HN}$ is $8.35, \mathrm{HA}$ is $4.55, \mathrm{HB}$ is 4.29, others are QG2 1.19; for E7-HN is 7.14, HA is $4.86, \mathrm{HB}$ is $1.88,1.97$ others are HG2 2.55, HG1 2.74; for G6-HN is 8.5 , HA is 3.79, 3.89; for C5-HN is 7.8, $\mathrm{HA}$ is $4.54, \mathrm{HB}$ is 3.03 ; for $\mathrm{V} 4-\mathrm{HN}$ is $8.07, \mathrm{HA}$ is $4.69, \mathrm{HB}$ is 2.64 , others are QQG 0.92; for P3-HA is 5.05, HB is 2.21, 2.51, others are HG2 2.06, HG1 1.74, $\mathrm{HD} 23.85, \mathrm{HD} 13.79$; for $\mathrm{L} 2-\mathrm{HN}$ is $7.79, \mathrm{HA}$ is $5.08, \mathrm{HB}$ is $1.78,2.04$, others are QD2 0.97, QD1 3.19, HG 1.48; for G1-HN is 8.53, HA is 3.63, HB is 4.28.

Figure 7 represents the FTIR analysis spectra. The scanning process was conducted on wave number $400-4000 \mathrm{~cm}^{-1}$ with resolution of $4 \mathrm{~cm}^{-1}$. The scanning results were percentage absorbance on specific wave number for every amide functional group of synthesized cyclotide [13]. Each amide has specific marker group and these are amida A shown at $3288.63 \mathrm{~cm}^{-1}$ represents the $\mathrm{N}-\mathrm{H}$ marker group; amida I at 1627.92 represents $\mathrm{C}=\mathrm{O}$ group; amida II and III at 1444.68 represents $\mathrm{C}-\mathrm{N}, \mathrm{N}-\mathrm{H}$ group; and amida IV at 698.23 represents O-C-N group. The determination of functional group was being done by comparing wave number of amide functional groups of the Kalata B2cyclotide to existing standard.

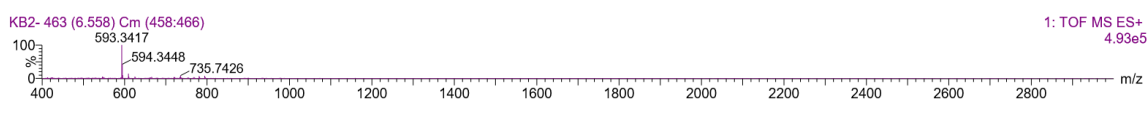

Figure 5. LC-MS of Kalata B2 cyclotide. 


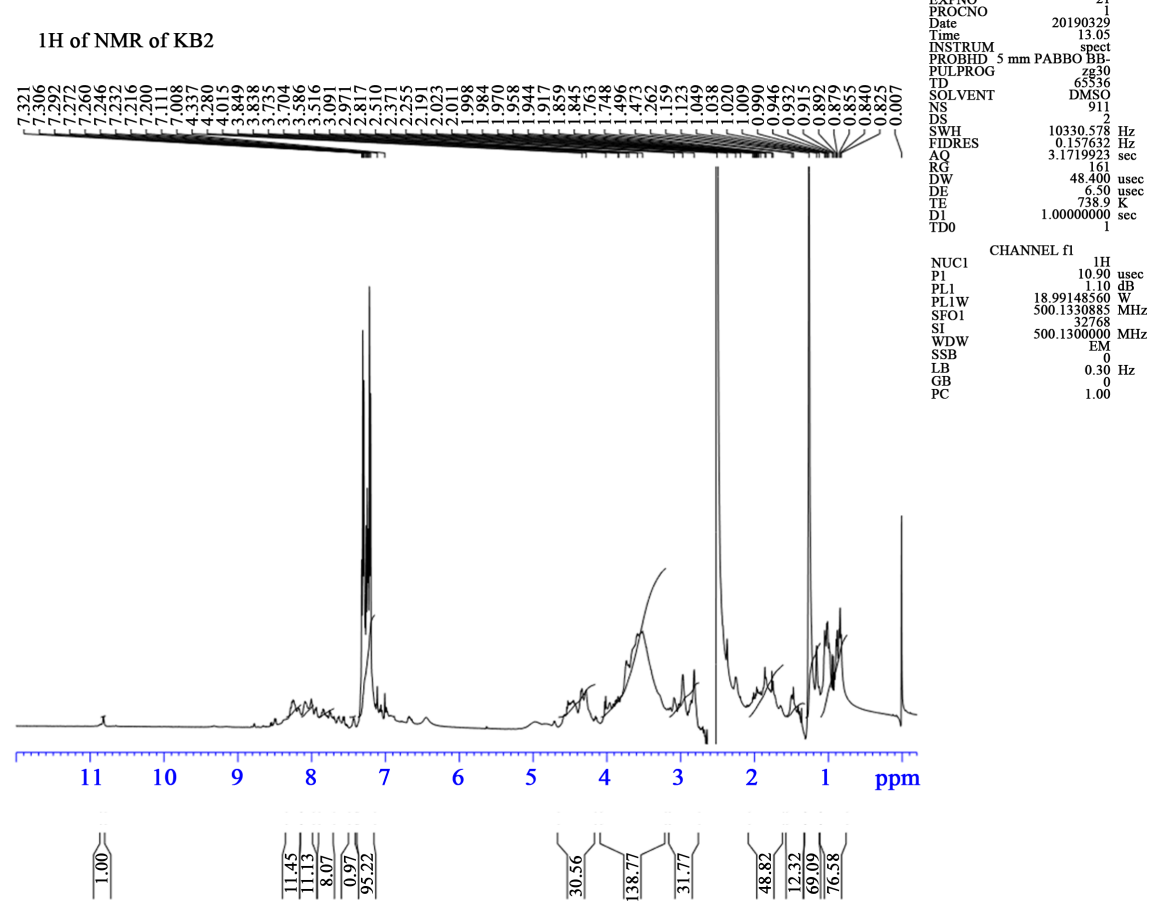

Figure 6. 1H NMR of KB2 cyclotide.

甲 SHIMADZU

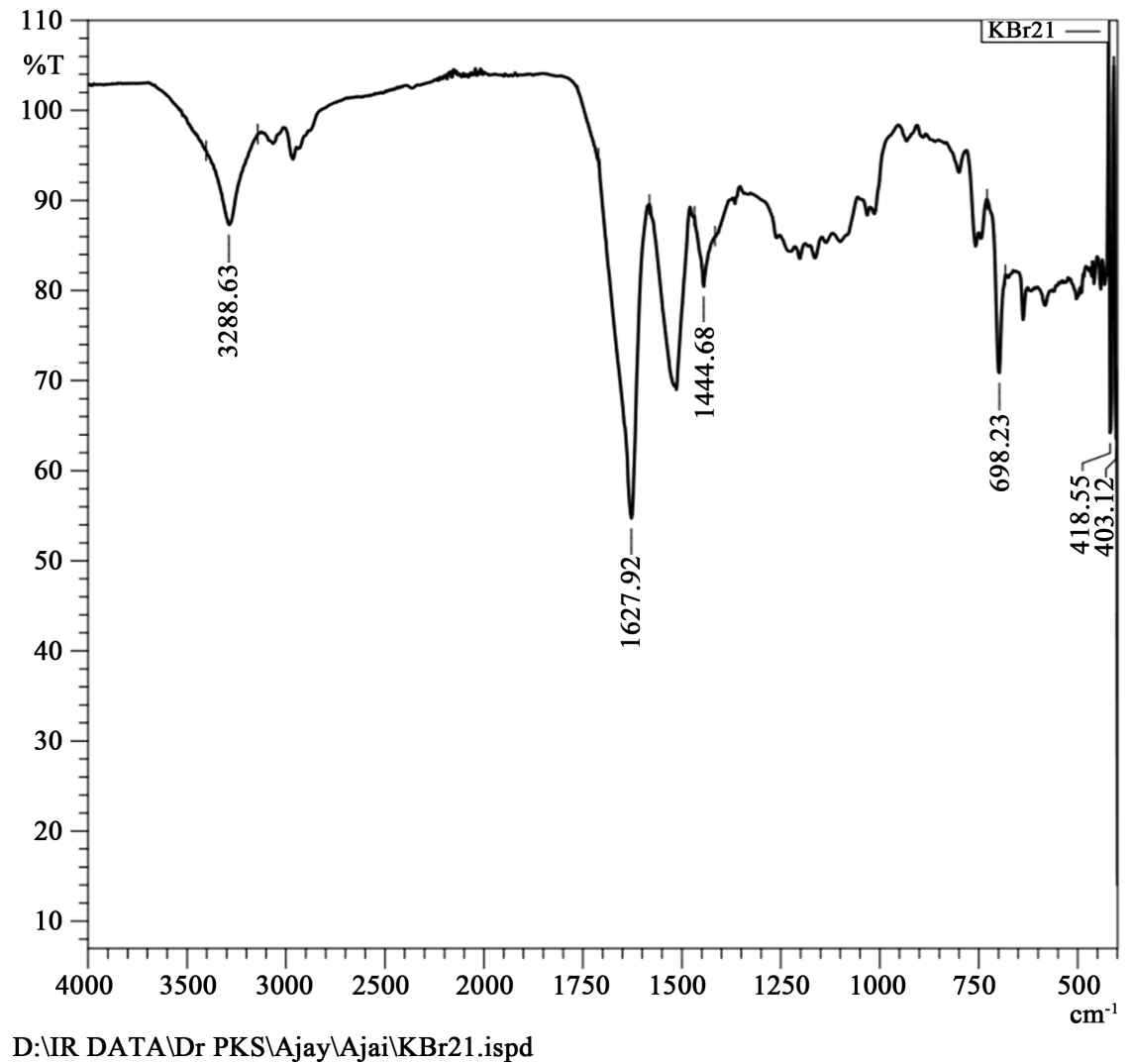

Figure 7. IR spectra of Kalata B2. 
B, C, D, E represents (Figure 8 and Figure 9) the different concentration of synthesised Kalata B2 peptide solution dissolved in water and make 400 microlitre solution. Sample B contained 15 microlitre Kalata B2 Peptide in 385 microlitre water, Sample C contained 25 microlitre peptide in 375 microlitre water, Sample D contained 50 microlitre peptide in 350 microlitre water, and sample E contained 100 microlitre peptide in 300 microlitre water. The near-UV CD spectrum $(>250 \mathrm{~nm}$ ) provides information on the tertiary structure. The signals obtained in the 250 - $300 \mathrm{~nm}$ region are due to the absorption, dipole orientation and the nature of the surrounding environment of the phenylalanine, tyrosine, cysteine (or S-S disulfide bridges) and tryptophan amino acids. Unlike in far-UV $\mathrm{CD}$, the near-UV CD spectrum cannot be assigned to any particular $3 \mathrm{D}$ structure.

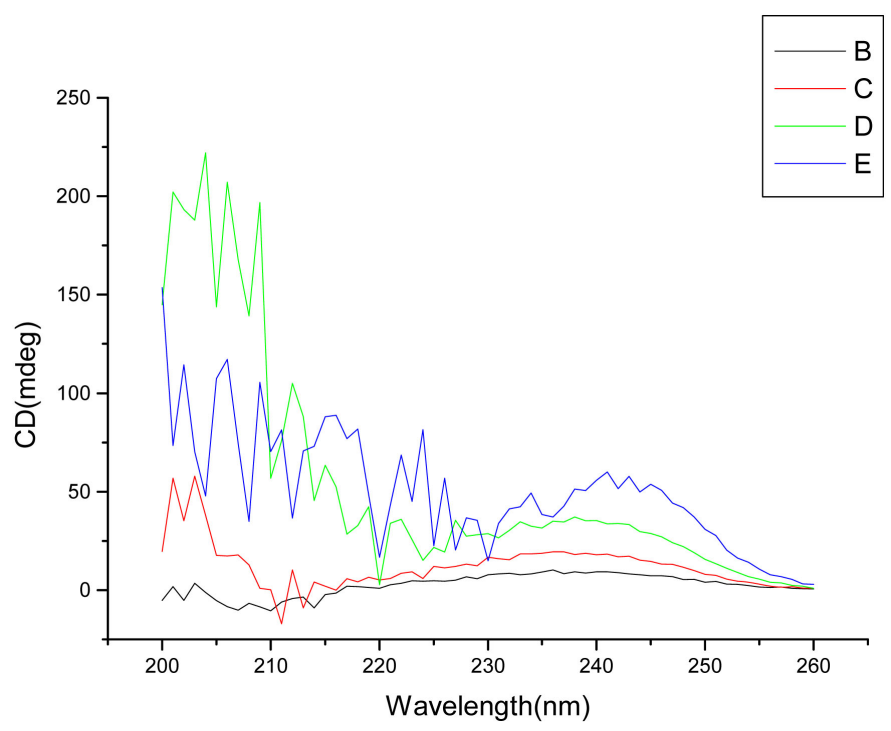

Figure 8. CD data of Kalata B2.

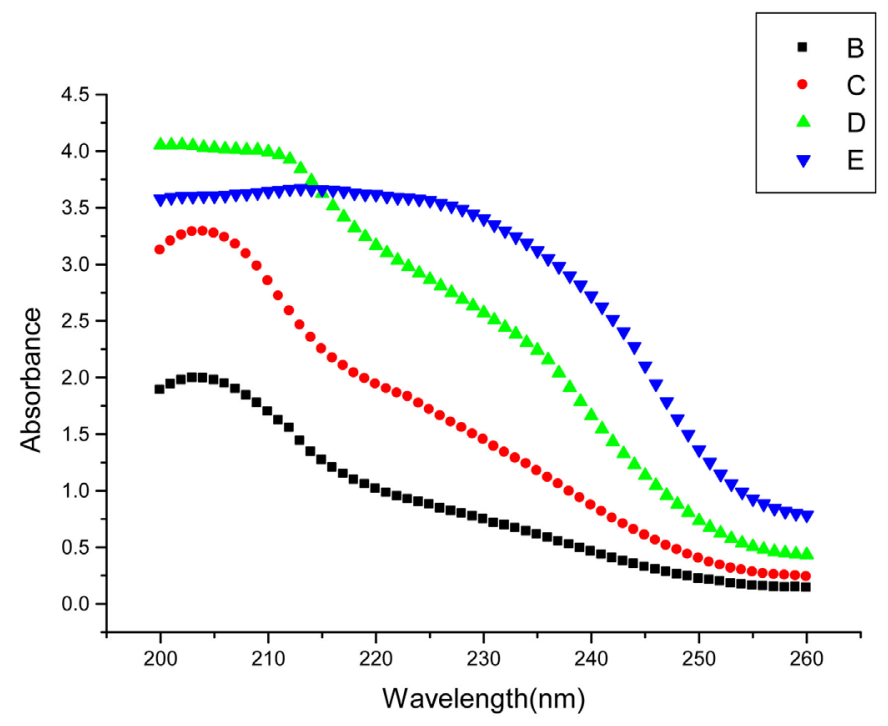

Figure 9. CD data with respect to absorbance. 


\section{Data spectra}

Integration of $\mathrm{CD}$ data from zero:

$\mathrm{i}=1 \rightarrow 61$

$\mathrm{x}=260 \rightarrow 200$

Area Peak at Width Height

$\begin{array}{llll}-152.66715 & 236 & -22 & 10.19916\end{array}$

Integration of $\mathrm{CD}$ data w.r.t absorbance from zero:

$\mathrm{i}=1 \rightarrow 61$

$\mathrm{x}=260 \rightarrow 200$

Area Peak at Width Height

$\begin{array}{llll}-51.91172 & 203 & -20 & 1.99388\end{array}$

\section{Conclusion}

Synthesis of Kalata B2 cyclotide has been achieved by manual SPPS method. The successful formation of Kalata B2 has been confirmed by UPLC-MS, LC-MS, 1HNMR, FT-IR. The purification of synthesized cyclotide had been done with RP-HPLC and the yield of cyclotide we got through this method is also good. The structure of Kalata B2 is confirmed by 1HNMR and FTIR. Our results conclusively prove that the manual SPPS method is cost-effective, low laborious and high yield producing methodology which effectively employed to synthesize Kalata B2 cyclotide and this cyclotide has been further studied for medicinal applications. Kalata B2 cyclotide had been reported for insecticidal activity against Helicoverpa armigera and that insecticidal activity was not unique to Kalata B1 cyclotide. We can also conclude form this study that the existing biological isolated active cyclotides can also be synthesized in laboratory to study their biological function in high yield because it is laborious, cost-effective, and, time-consuming methods to isolate cyclic peptides (cyclotide) from natural sources and also not ethical practice.

\section{Acknowledgements}

The authors are thankful to Genpro Biotech Laboratory, Noida, New Delhi and its team to provide the facility for the synthesis of biological importance Kalata B2 cyclotide and AIRF, JNU, Delhi, for characterization of synthesized Kalata B2 cyclotide.

\section{Conflicts of Interest}

The authors declare no conflicts of interest regarding the publication of this paper.

\section{References}

[1] Gould, A., Ji, Y.B., Aboye, T.L. and Camarero, J.A. (2011) Cyclotides, a Novel Ultrastable Polypeptide Scaffold for Drug Discovery. Current Pharmaceutical Design, 17, 4294-4307. https://doi.org/10.2174/138161211798999438 
[2] Colgrave, M.L. and Craik, D.J. (2004) Thermal, Chemical, and Enzymatic Stability of the Cyclotide Kalata B1: The Importance of Cyclic Cystine knot. Biochemistry, 43, 5965-5975. https://doi.org/10.1021/bi049711q

[3] Li, P. and Roller, P.P. (2002) Cyclization Strategies in Peptide Derived Drug Design. Current Topics in Medicinal Chemistry, 2, 325-341. https://doi.org/10.2174/1568026023394209

[4] Durieux, J.P. and Nyfeler, R. (1994) Peptides. Proceedings of the 23rd European Peptide Synposium, Braga, Portugal, 4-10 September 1994.

[5] de Veer, S.J., Weidmann, J. and Craik, D.V. (2017). Cyclotides as Tools in Chemical Biology. Accounts of Chemical Research, 50, 1557-1565. https://doi.org/10.1021/acs.accounts.7b00157

[6] Norman, Anderson and Craik (2005) Isolation, Solution Structure, and Insecticidal Activity of Kalata B2, a Circular Protein with a Twist: Do Möbius Strips Exist in Nature. Biochemistry, 44, 851-860. https://doi.org/10.1021/bi047837h

[7] Oguis, G.K., Kan, M.-W. and Craik, D.J. (2017) Cyclotides: Plant Defence Toxins. Springer Science and Business Media Dordrecht, 225.

[8] Katsara, M., Tselios, T., Deraos, S., Deraos, G. and Matsoukas, M.T. (2006) Round and Round We Go: Cyclic Peptides in Disease. Current Medicinal Chemistry, 13, 2221-2232. https://doi.org/10.2174/092986706777935113

[9] Durieux, J.P. and Nyfeler, R. (1995) Peptides 1994. In: Maia, H.L.S., Ed., Proceedings of the 23rd European Peptide Symposium, Braga 1994, ESCOM Publishers, Leiden, 165.

[10] Büllesbach, E.E. and Schwabe, C. (1991) Total Synthesis of Human Relaxin and Human Relaxin Derivatives by Solid-Phase Peptide Synthesis and Site-Directed Chain Combination. J. Biol. Chem., 266, 10754-10761.

[11] Mergler, M. and Nyfeler, R. (1996) In: Epton, R., Ed., Proceedings of the 4th International Symposium on Innovation and Perspectives in SPPS, Edinburgh 1995, Mayflower Scientific Ltd., Birmingham, 42.

[12] Moroder, L., Besse, D., Musiol, H.J. and Rudolph-Böhmer, S.F. (1996) Biopolymers, 40, 207234.

[13] Kong, J. and Yu, S. (2007) Fourier Transform Infrared Spectroscopic Analysis of Protein Secondary Structures. Acta Biochimica et Biophysica Sinica, 39, 549-559. https://doi.org/10.1111/j.1745-7270.2007.00320.x 